\title{
Metamaterial Inspired Patch Antenna for ISM Band by Adding Single-Layer Complementary Split Ring Resonators
}

\author{
Rajni*, Gursharan Kaur*, Anupma Marwaha** \\ * Department of ECE, SBSSTC (PTU), Kapurthala, Punjab, India \\ ** Department of ECE, SLIET (Deemed University), Longowal, Punjab, India
}

\begin{tabular}{|c|c|}
\hline Article Info & ABSTRACT \\
\hline Article history: & In this work, we propose the design of metamaterial inspired compact \\
\hline Received Apr 22, 2015 & $\begin{array}{l}\text { circular patch antennas loaded with complementary split-ring resonators } \\
\text { (CSRRs) for ISM band operation. CSRRs have been incornorated }\end{array}$ \\
\hline Revised Aug 12, 2015 & horizontally inside the dielectric. The various models of CSRR loaded \\
\hline Accepted Aug 29, 2015 & $\begin{array}{l}\text { antennas with different patch radius are produced and are evaluated } \\
\text { numerically with Ansoft HFSS software. The results of the suggested }\end{array}$ \\
\hline Keyword: & $\begin{array}{l}\text { antenna designs are presented that reveal a comparable impedance match and } \\
\text { radiation characteristics with those of a normal patch antenna without CSRR. }\end{array}$ \\
\hline $\begin{array}{l}\text { Circular patch antena } \\
\text { Complementary split ring }\end{array}$ & $\begin{array}{l}\text { The proposed antennas yield high levels of miniaturization and similar } \\
\text { performance to the conventional patch antenna at the } 2.45 \mathrm{GHz} \text {. }\end{array}$ \\
\hline
\end{tabular}

Copyright () 2015 Institute of Advanced Engineering and Science.

High frequency structuure

simulator (HFSS)

Metamaterial antenna

All rights reserved.

Miniature antenna

\section{Corresponding Author:}

Rajni,

Department of Electronics and Communication Engineering,

Punjab Technical University,

Kapurthala, Punjab, India.

Email: rajni_c123@yahoo.co.in

\section{INTRODUCTION}

Nowadays the small size antenna became a significant part of the overall package volume due to greater integration of electronics. This raised the demand for minimization in antenna size. The base of all these researches arouse from the metamaterial property coined by Victor Veselago in 1968 [1]. The instigation of the metamaterials (MTMs), with unnatural exotic properties has provided a different approach to design electrically-small antenna (ESA) systems. Split-ring resonators (SRRs) and their dual, complementary split-ring resonators (CSRRs) are used widely to manufacture metamaterials [2]-[6]. In 2004, CSRRs were firstly introduced by Falcone et al., proved to possess negative permittivity [6]. By using the concepts of duality and complementarity, Falcone et al. showed that the efficient permittivity of a dielectric comprising CSRRs (regular cuts etched from a metallic disk) can be adapted to desired frequency when the dielectric is energized by the electric field polarized over the axis of the CSRRs. Hence, the resonant frequency of a complementary structure can be reduced with various slots. So miniaturization, in a broader concept, can be acquired by making a high frequency antenna to radiate at a lower frequency. This is achieved by loading the CSRRs inside the patch cavity. CSRR have been widely used in ESA designs [7] and the miniaturization of known designs [8]-[14]. A plethora of miniaturization techniques is available in literature like insertion of slots on the radiating patch [15], design of fractal based antenna [16]-[17] and use of artificial materials such as high impedance surfaces (HIS), reactive impedance surfaces (RIS), magnetodielectrics and Defected Ground Structure (DGS) based antennas [18] but these methods provide little miniaturization of about $38 \%$ whereas incorporation of CSRRs inside the dielectric provides miniaturization upto $78 \%$ [12]. 
In this work, various microstrip patch antennas loaded with CSRR is presented, that operate in the ISM band. A metamaterial inspired design approach is presented to design very small patch antennas which are thin having low weight, cheap and easy to fabricate. With metamaterial inspired, it is meant that the parasitic structure is not metamaterial itself; but it is inspired by that possibility. The reduced size of patch antennas is obtained over a fine impedance match, along a reflection coefficient of beyond - $20 \mathrm{~dB}$ in every case. In this work, miniaturized antennas upto 1/15 surface area reduction, are observed in simulations with acceptable degradation of impedance or pattern.

\section{ANTENNA DESIGN}

A radiating circular patch is situated at the top of a cylindrical dielectric, aided with circular ground plane having length identical to the substrate. The patch is excited with microstrip line feed. Within the patch and ground plane a metallic disk is positioned horizontally and CSRRs of different radius are incorporated by skimming the disk material.

\subsection{Conventional Circular Patch Antenna Design}

Figure 1 depicts the design of conventional circular patch antenna without CSRR. A circular copper patch of radius $22.1 \mathrm{~mm}$ is etched on the top of a circular Rogers RT/duroid 5870 substrate of radius $46.2 \mathrm{~mm}$ having thickness $2.34 \mathrm{~mm}$, dielectric constant $\varepsilon_{r} 2.33$ and dielectric loss tangent $\delta=0.0012$, supported by a copper ground plane of same radius. A $50 \Omega$ copper microstrip line of width $1.5 \mathrm{~mm}$, with an SMA connection situated on edge of the dielectric is feeding the patch. The patch radius is optimized to resonate the antenna at $2.45 \mathrm{GHz}$.

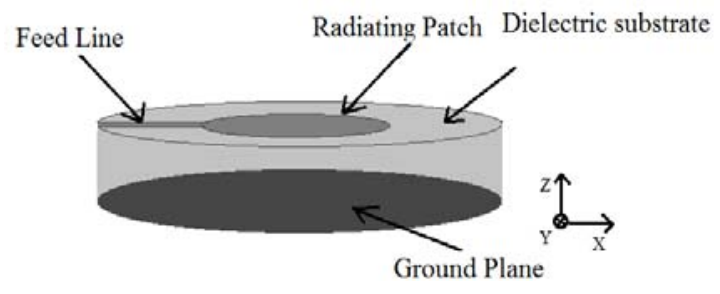

Figure 1. Conventional circular patch without CSRR

\section{2 . Design Analysis of Circular Patch Antenna}

The radius of a circular patch, $r$ is given by (Balanis, 1982) [19] is:

$r=\frac{F}{\left\{1+\frac{2 h}{\pi \varepsilon_{r} F}\left[\ln \left(\frac{\pi F}{2 h}\right)+1.7726\right]\right\}^{\frac{1}{2}}}$

where $\varepsilon_{r}$ is substrate dielectric constant

$h$ is substrate height

$\mathrm{F}$ is operational frequency given by Equation (2):

$F=\frac{8.791 \times 10^{9}}{f_{r}\left(\sqrt{\varepsilon_{r}}\right)}$

The Equation (1) is without considering the fringing effects. Fringing results in the electrically larger patch, So the effective radius of patch, $r_{e}$ is is given by Equation (3).

$$
r_{e}=r\left\{1+\frac{2 h}{\pi \varepsilon_{r} r}\left[\ln \left(\frac{\pi r}{2 h}\right)+1.7726\right]\right\}^{1 / 2}
$$

Hence, the resonant frequency is given by Equation (4).

$$
f_{r}=\frac{1.8412 v_{0}}{2 \pi r_{e} \sqrt{\varepsilon_{r}}}
$$

where $v_{0}$ is the free space speed of light. 


\section{3 . Antenna Design with CSRR}

For miniaturization, a copper disk consisting of a CSRR is inserted horizontally $0.78 \mathrm{~mm}$ below the radiating patch as illustrated in Figure 2. Three different models of circular patch antenna are designed with different patch radii. For all the cases, the ground plane radius is taken twice of the patch, with substrate thickness $2.34 \mathrm{~mm}$, and the microstrip feed line width is taken $1.5 \mathrm{~mm}$ for $50 \Omega$ characteristic impedance; all these are similar to the conventional patch.

Following three miniature versions of conventional circular patch antenna are designed:

1) Model 1: In model 1, the circular patch antenna with patch radius $12 \mathrm{~mm}$, a disk of radius $r_{1}$, $23 \mathrm{~mm}$ containing single ring $(\mathrm{n}=1)$ having radius $r_{2}, 7.1 \mathrm{~mm}$, thickness $t, 1.5 \mathrm{~mm}$ and gap width $d, 1.15 \mathrm{~mm}$ is inserted $0.78 \mathrm{~mm}$ below the patch .

2) Mode1 2: In model 2, the circular patch antenna with patch radius $10 \mathrm{~mm}$, a disk of radius $r_{1}$, $9.8 \mathrm{~mm}$ containing two rings $(\mathrm{n}=2)$ with outer ring radius $r_{2}, 5.3 \mathrm{~mm}$, thickness $t, 1.16 \mathrm{~mm}$, gap width $d$, $1.46 \mathrm{~mm}$ and spacing between the rings $\mathrm{s}, 0.74$ is inserted $0.78 \mathrm{~mm}$ below the patch .

3) Mode1 3: In model 3, the circular patch antenna with patch radius $6 \mathrm{~mm}$, a disk of radius $r_{1}$, $10.7 \mathrm{~mm}$ containing three rings $(\mathrm{n}=3)$ with outer ring radius $r_{2}, 9.9 \mathrm{~mm}$, thickness $t, 1.65 \mathrm{~mm}$, spacing between rings $s, 1.05 \mathrm{~mm}$ and gap width $d, 1.9 \mathrm{~mm}$ is inserted $0.78 \mathrm{~mm}$ below the patch.

4) Model 4: In model 4, the circular patch antenna with patch radius 5.8mm, a disk of radius $r_{1}$, $10.5 \mathrm{~mm}$ containing three rings $(\mathrm{n}=4)$ with outer ring radius $r_{2}, 9 \mathrm{~mm}$, thickness $t, 1.3 \mathrm{~mm}$, spacing between rings $s, 0.7 \mathrm{~mm}$ and gap width $d, 1.6 \mathrm{~mm}$ is inserted $0.78 \mathrm{~mm}$ below the patch.

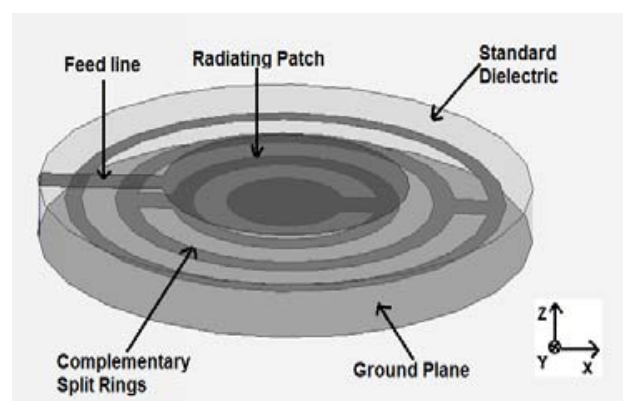

Figure 2. The miniaturized patch antenna using CSRR (Model 3 with $n=3$ )

The circular disk geometry, presented in Figure 3., is optimized through changing the number of rings, $\mathrm{n}$, the outer ring radius, $r_{2}$, thickness of the rings, $t$, spacing between the rings, $s$, and the width of the cut, $d$. The values of $t, d$ and $s$ are selected to be the equal for all of the CSRRs, and the disk radius $r_{1}$, is kept less than the ground radius.

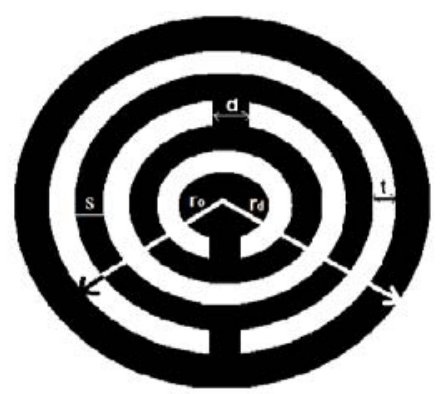

(a) $n=3$

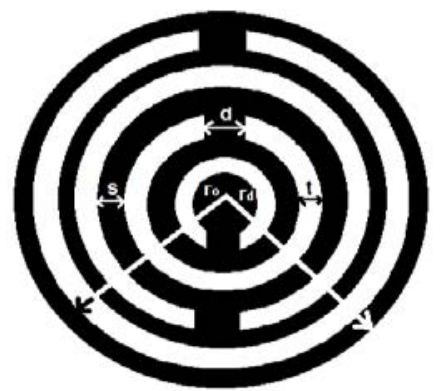

(b) $n=4$

Figure 3. Circular disk containing the CSRR (a) $n=3$ (b) $n=4$

To prevent interaction with the SMA connector, the disk radius, $r_{1}$, for every case is chosen to be smaller than the substrate. The $r_{1}$ values for various patch geometries are tabulated in Table 1 . 
Table 1. Values of CSRR parameters for three models with different patch radius

\begin{tabular}{ccccc}
\hline MODEL & MODEL 1 & MODEL 2 & MODEL 3 & MODEL 4 \\
\hline Patch Radius (in mm) & 12 & 10 & 6 & 5.8 \\
Disk radius( $\mathrm{r}_{1}$ ) (in mm) & 23 & 9.8 & 10.7 & 10.5 \\
Outer ring radius( $\mathrm{r}_{2}$ ) (in mm) & 7.1 & 5.3 & 9.9 & 9 \\
spacing (s) (in mm) & $\ldots$ & 0.74 & 1.05 & 0.7 \\
Thickness (t) (in mm) & 1.5 & 1.14 & 1.65 & 1.3 \\
Gap width(d) (in mm) & 1.15 & 1.46 & 1.9 & 1.6 \\
\hline
\end{tabular}

\section{RESULTS AND DISCUSSION}

After optimizing the patch and modeling the geometry of CSRR the antenna is analyzed for far field calculations. The frequency responses and reflection coefficient for all the cases is calculated and presented in various plots. It is observed that various CSRR geometries produce different patch antennas with different patch radius, resonating at same frequency, but with varying performances. The geometry of the CSRR for a desired level of miniaturization is resolved with its simulation with full wave solver HFSS. HFSS software is based on Finite Element Method (FEM), is nowadays used in designing and analysis of complex antennas.

\subsection{Conventional Circular Patch Antenna}

The frequency response and reflection coefficient plot of conventional patch antenna is shown in Figure 4. It is noticeable from Figure 4, conventional circular patch antenna resonates at $2.45 \mathrm{GHz}$ with reflection coefficient below $-10 \mathrm{~dB}$ as desired with circular patch radius as $22.1 \mathrm{~mm}$.

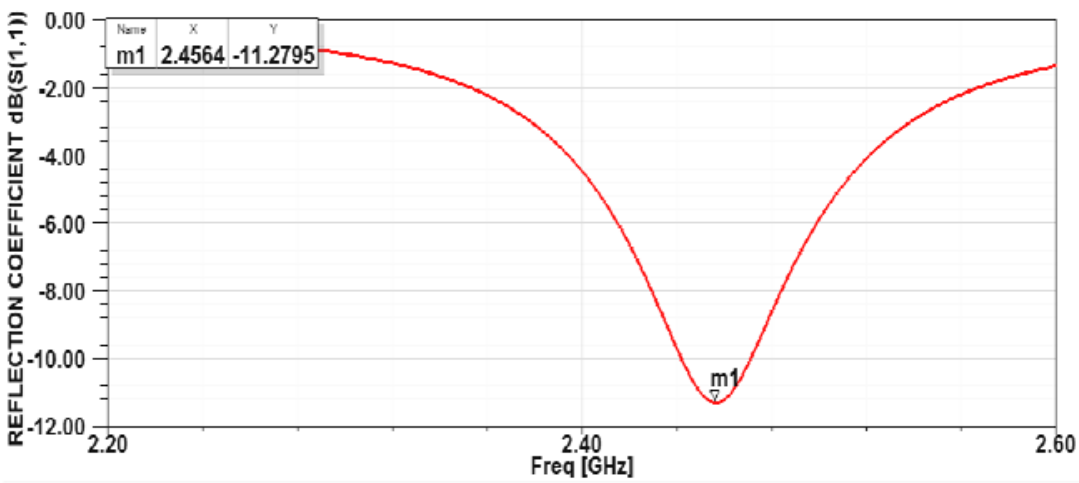

Figure 4. Reflection Coefficient $\left(\mathrm{S}_{11}\right)$ plot of the normal patch antenna without CSRR

\subsection{Model 1 (Circular patch with radius $12 \mathrm{~mm}$ )}

The frequency response and reflection coefficient plot of model 1 is shown in Figure 5. The antenna resonates at $2.46 \mathrm{GHz}$ with reflection coefficient below $-20 \mathrm{~dB}$ as desired. The results achieved reduced patch radius of $12 \mathrm{~mm}$ and area reduction of $1 / 4$ of the conventional patch antenna.

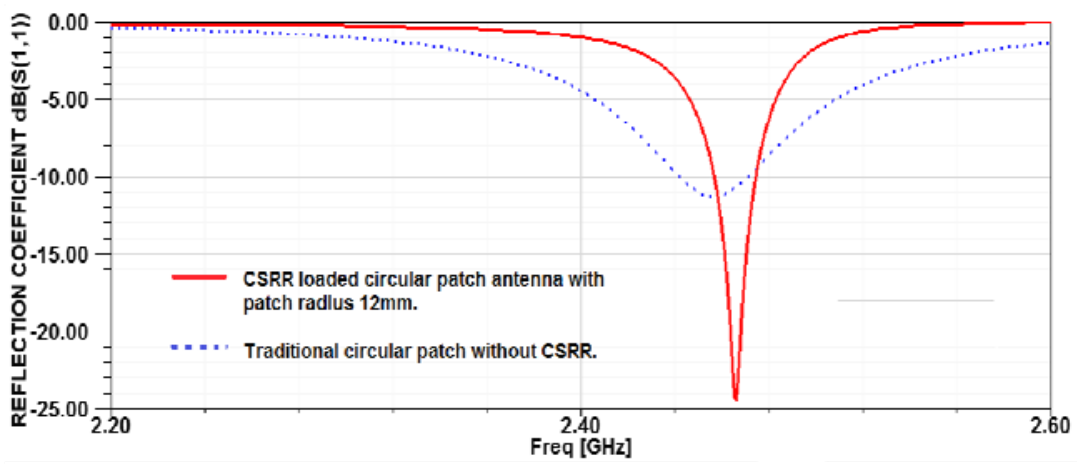

Figure 5. Reflection Coefficient $\left(\mathrm{S}_{11}\right)$ plot of model 1 


\subsection{Model 2 (Circular patch with radius $10 \mathrm{~mm}$ )}

The frequency response and reflection coefficient plot of model 2 is shown in Figure 6 . The reflection coefficient of this antenna is below $-25 \mathrm{~dB}$ and it resonates at $2.47 \mathrm{GHz}$ when the radius of the patch is $10 \mathrm{~mm}$. This design results in area reduction of $1 / 5$ of the conventional patch antenna.

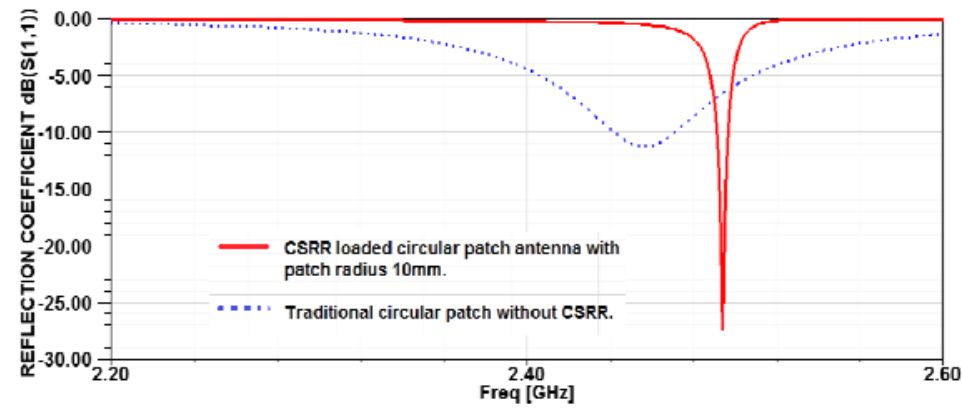

Figure 6. Reflection Coefficient $\left(\mathrm{S}_{11}\right)$ plot of model 2

\subsection{Model 3 (Circular patch with radius $6 \mathrm{~mm}$ )}

The frequency response and reflection coefficient plot of model 3 is shown in Figure 7. The reflection coefficient of this antenna is below $-25 \mathrm{~dB}$ and its resonance frequency is $2.46 \mathrm{GHz}$. This antenna design achieve reduced patch radius of $6 \mathrm{~mm}$ and area reduction of $1 / 14$ of the conventional patch antenna.

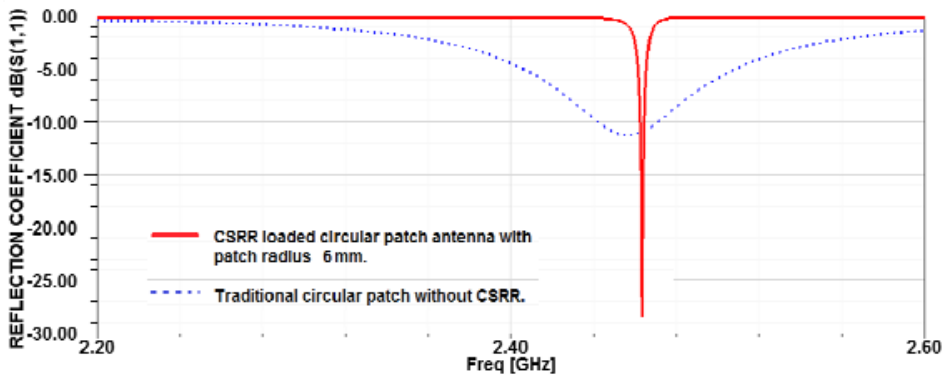

Figure 7. Reflection Coefficient $\left(\mathrm{S}_{11)}\right.$ plot of model 3

\subsection{Model 4 (Circular patch with radius $5.8 \mathrm{~mm}$ )}

The frequency response and reflection coefficient plot of model 4 is shown in Figure 8 . The reflection coefficient of this antenna is nearly $-25 \mathrm{~dB}$ and its resonance frequency is $2.48 \mathrm{GHz}$. This antenna design achieves further reduced patch radius of $5.8 \mathrm{~mm}$ and area reduction of $1 / 15$ of the conventional patch antenna. Due to the degradation in antenna volume, the radiation efficiency and the bandwidth of the resultant patch antenna get affected but its properties stay fairly good.

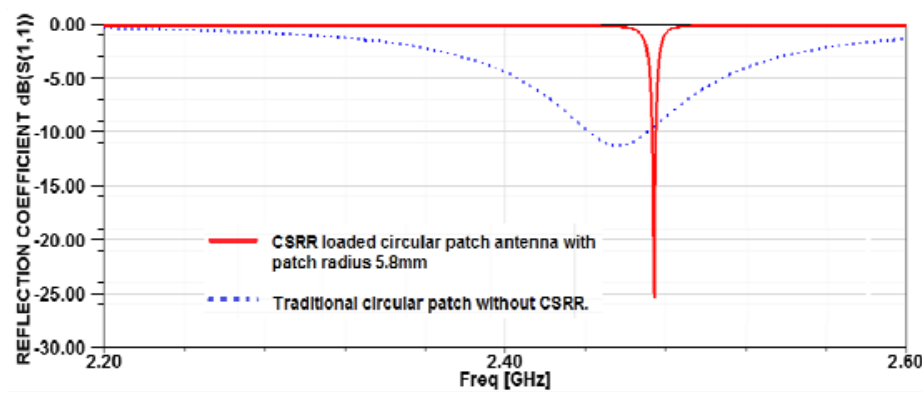

Figure 8. Reflection Coefficient $\left(\mathrm{S}_{11)}\right.$ plot of model 4 
An electric current is induced on the metal, when an SRR is placed in time varying normal magnetic field, gaining peak value at the SRR resonant frequency. Similarly by duality, magnetic current is expected to be generated among the CSRR slots, approaching the optimum value at the CSRR resonance frequency, when CSRR was kept in a time varying perpendicular electric field. This effect is shown in Figure 9, which presents an electric field intensity plot on the CSRR screen for a miniaturized patch antenna with radius $6 \mathrm{~mm}$. It is observed that the electric field intensity is strong at the edges of the slots. When disk radius is decreased, the number of slots in the disk increases in order to achieve equivalent resonant frequency and a fine impedance matching.

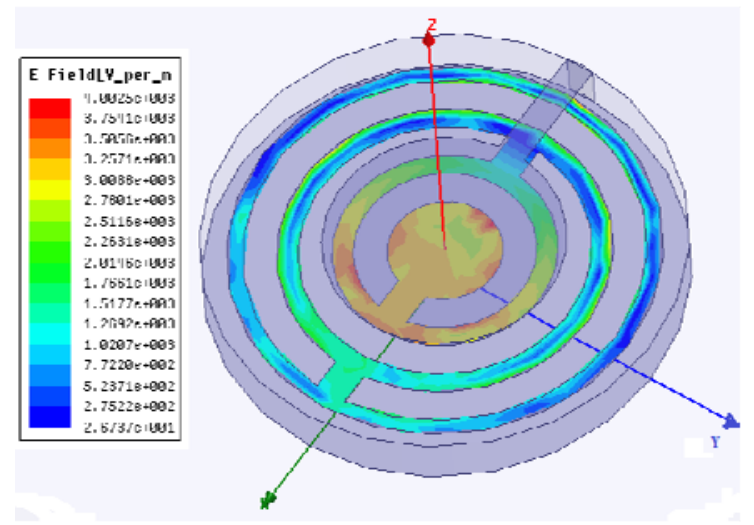

Figure 9. Electric field intensity at the surface of the CSRR

The simulated 2-D patterns of gain of conventional patch antenna shown in Figure 10. And the proposed miniature antennas have been presented in Figure 11 (a) (with patch radius 12mm), Figure 11(b) (with patch radius $10 \mathrm{~mm}$ ), Figure 12 (a) (with patch radius $6 \mathrm{~mm}$ ) and Figure 12 (b) (with patch radius $5.8 \mathrm{~mm}$ ) respectively. The broadside behavior of radiation pattern is preserved, but due to the decrease in radiation efficiency, the achieved gain is reduced by making the antenna smaller.

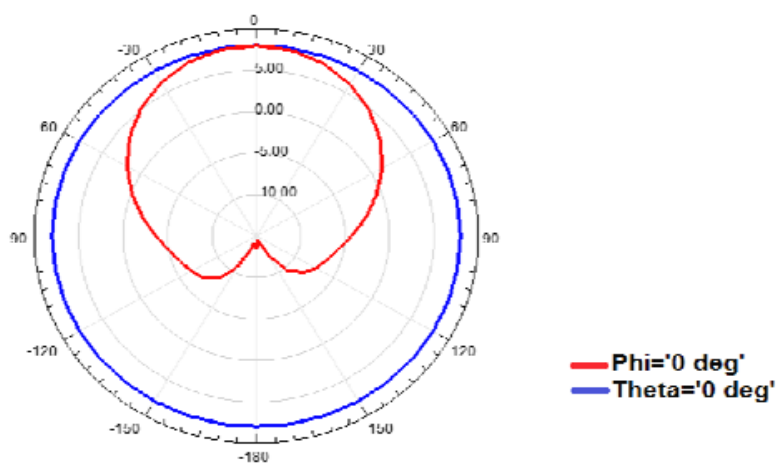

Figure 10. Simulated gain pattern of conventional patch antenna

The position of the disk containing CSRR is decided by accessible substrate thicknesses. The substrate thickness of $0.78 \mathrm{~mm}$ used in this work is a standard value fabricated by Rogers Corporation. Also further optimizations having CSRR positioned at $1.56 \mathrm{~mm}$ below the patch presented the same results as those achieved for a distance of $0.78 \mathrm{~mm}$. 


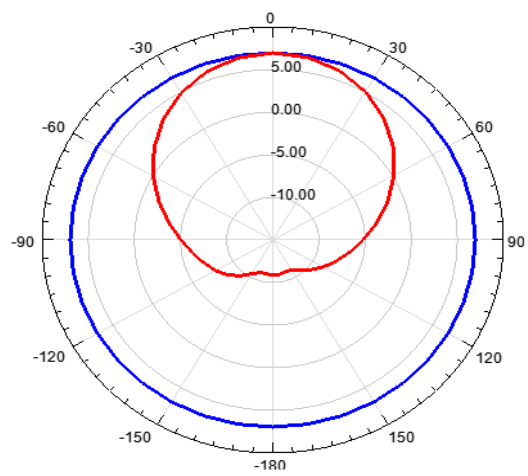

(a) Model 1 (patch radius $12 \mathrm{~mm}$ )

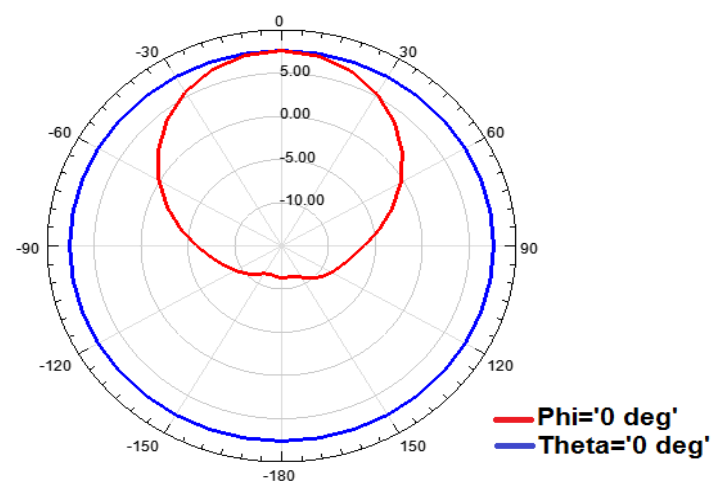

(b) Model 2(patch radius $10 \mathrm{~mm}$ )

Figure 11. Simulated gain patterns of (a) model 1 for $n=1$ (b) model 2 for $n=2$

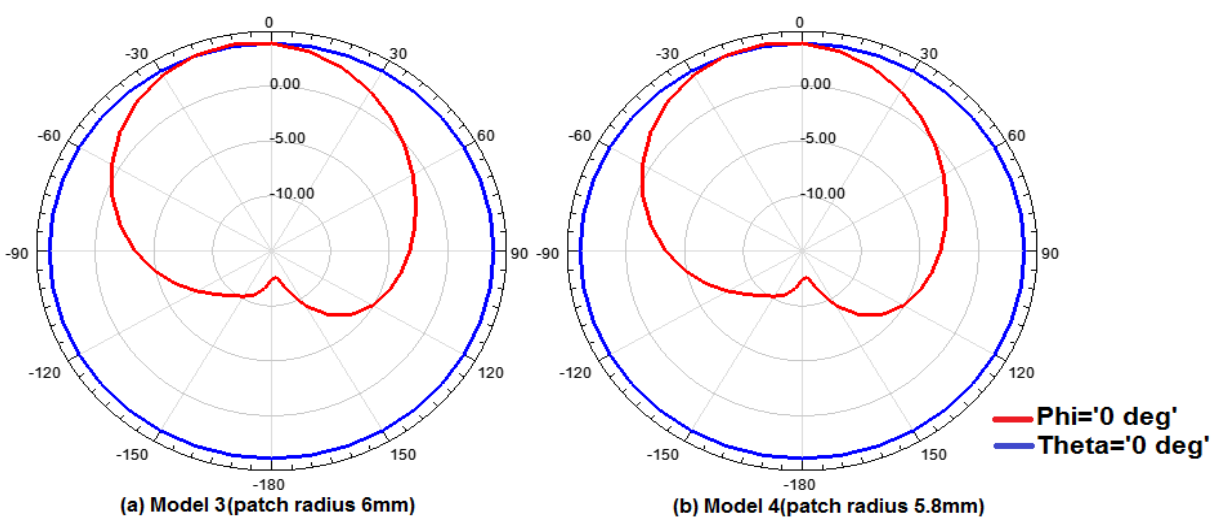

Figure 12. Simulated gain patterns of (a) model 3 for $n=3$ (b) model 4 for $n=4$

\section{CONCLUSION}

A highly miniaturized patch antennas design methodology is presented. By inserting a disk containing CSRRs into conventional patch, the radius of the patch can be decreased significantly without disturbing the impedance match and the field pattern. The construction of these miniature antennas is simple and can be produced with less effort at low cost. Even further reductions in the antenna size are possible, but the fractional bandwidth and radiation efficiency also get reduced that might proved to be objectionable. The proposed design methodology can be used further in other patch designs like rectangular patch. Preliminary investigations performed using miniaturized rectangular patch antennas reveal performances comparable to those achieved with circular patch. Moreover, the proposed optimization system will prove helpful in designing patch antennas for the multi-band operations.

\section{REFERENCES}

[1] V. G. Veselago, "The electrodynamics of substances with simultaneously negative value $\varepsilon$ and $\mu$," Sov. Phys. Uspekekhy, Vol. 10, No. 4, pp. 509-514, 1968.

[2] R. Marques, F. Martin, and M. Sorolla, "Metamaterials with Negative Parameters: Theory, Design and Microwave Applications," New York: Wiley, 2008.

[3] S. Hrabar, J. Bartolic, and Z. Sipus, "Waveguide miniaturization using uniaxial negative permeability metamaterial,” IEEE Trans. Antennas Propag., Vol. 53, No. 1, pp. 110-119, 2005.

[4] J. D. Baena, J. Bonache, F. Martin, R. Marques, F. Falcone, T. Lopetegi, M. A. G. Laso, J. Garcia, I. Gil, and M. Sorolla, "Equivalent-circuit models for split-ring resonators and complementary split-ring resonators coupled to planar transmission lines," IEEE Trans. Microw. Theory Tech., Vol. 53, No. 4, pp. 1451-1461, 2005.

[5] P. K. Singhal, Bimal Garg, "Design and Characterization of Compact Microstrip Patch Antenna Using "Split Ring" Shaped Metamaterial Structure," International Journal of Electrical and Computer Engineering (IJECE), Vol. 2, No. 5, pp. 655-662, 2012. 
[6] Falcone, T. Lopetegi, J. D. Baena, R. Marques, F. Martin, and M. Sorolla, "Effective negative-epsilon stopband microstrip lines based on complementary split ring resonators," IEEE Microw. Wireless Compon. Lett., Vol. 14, No. 14, pp. 280-282, 2004.

[7] K. B. Alici and E. Ozbay, "Electrically small split ring resonator antennas," J. Appl. Phys., Vol. 101, pp. 083-104, 2007.

[8] F. Bilotti, A. Alú, and L. Vegni, "Design of miniaturized metamaterial patch antennas with -negative loading," IEEE Trans. Antennas Propag., Vol. 56, No. 6, pp. 1640-1647, 2008.

[9] M. Palandoken, A. Grede, and H. Henke, "Broadband microstrip antenna with left-handed metamaterials," IEEE Trans. Antennas Propag., Vol. 57, No. 2, pp. 331-338, 2009.

[10] M. C. Tang, S. Xiao, T. Deng, D. Wang, J. Guan, B. Wang, and G. Ge, "Compact UWB antenna with multiple band-notches for WiMAX and WLAN," IEEE Trans. Antennas Propag., Vol. 59, No. 4, pp.1372-1376, 2011.

[11] Y. Dong, H. Toyao, and T. Itoh, "Design and characterization of miniaturized patch antennas loaded with complementary split-ring resonators," IEEE Trans. Antennas Propag., Vol. 60, No. 2, pp.772-785, 2012.

[12] R. O. Ouedraogo, E. J. Rothwell, A. R. Diaz, K. Fuchi, and A. Temme, "Miniaturization of patch antennas using a metamaterial-inspired technique," IEEE Trans. Antennas Propag., Vol. 60, No. 5, pp. 2175-2181, 2012.

[13] J. B. Pendry, A. J. Holden, D. J. Robbins, and W. J. Stewart, "Magnetism from conductors and enhanced nonlinear phenomena," IEEE Trans. Microw.Theory Tech., Vol. 47, No. 11, pp. 2075-2084, 1999.

[14] O Necibi, A Ferchichi, T. P Vuong, A Gharsallah, "Miniaturized CSRR TAG Antennas for 60GHz Applications," International Journal of Electrical and Computer Engineering (IJECE), Vol. 4, No. 1, pp. 64-74, 2014.

[15] Kuldeep Kumar Parashar, "Design and Analysis of I-Slotted Rectangular Microstrip Patch Antenna for Wireless Application," International Journal of Electrical and Computer Engineering (IJECE), Vol. 4, No. 1, pp. 31-36, 2014.

[16] Satyandra Singh lodhi, P. K. Singhal, V. V. Thakare, "Design and Analysis of Tripple Band Koch Fractal Yagi Uda Antenna," International Journal of Electrical and Computer Engineering (IJECE), Vol. 3, No. 4, pp. 456-460, 2013.

[17] Simarpreet Kaur, Rajni, Anupma Marwaha, "Fractal Antennas: A Novel Miniaturization Technique for Next Generation Networks," International Journal of Engineering Trends and Technology (IJETT), Vol. 9, No. 15, 2014.

[18] Gurpreet Singh, Rajni, Ranjit Singh Momi, "Microstrip Patch Antenna with Defected Ground Structures for Bandwidth Enhancement," International Journal of Computer Applications, Vol. 73, No. 9, pp. 14-17, 2013.

[19] Balanis C. A, "Handbook of Microstrip Antennas,” John Wiley and Sons New York, 1982.

\section{BIOGRAPHIES OF AUTHORS}

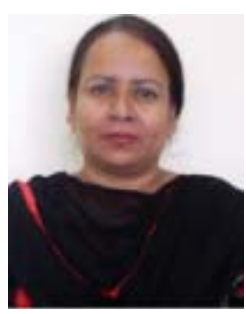

Rajni is currently Associate Professor at SBS StateTechnical Campus Ferozepur, India. She has completed her M.E. from NITTTR, Chandigarh, India and B.Tech from NIT, Kurukshetra India. She is pursuing her Ph.D. in metamaterial antennas. She has approx. 17 years of academic experience. She has authored a number of research papers in International journals, National and International conferences. Her areas of interes include Wireless communication and Antenna design.

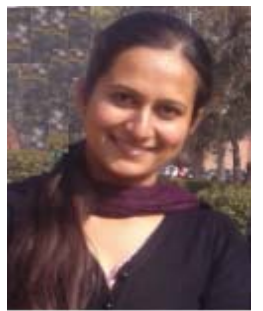

Gursharan Kaur is currently pursuing M.Tech from SBS State Technical Campus, Ferozepur, India. She has completed B.Tech from PTU Jalandhar in 2013. Her area of interest is Antenna design.

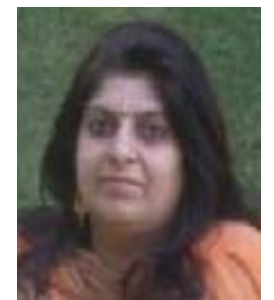

Dr Anupma Marwaha is currently Associate Professor at Sant Longowal Institute of Engg. \& Tech, Logowal (Sangrur). She has done her Ph.D from GNDU, Amritsar, M. Tech. from REC Kurukshetra (Now NIT, Kurukshetra), B.E from Punjab University,Chandigarh. She has 22 years of academic experiemce. She has authored 25 research papers in International and National Journals and 50 research papers in National and International conferences. She has supervised 03 Ph.D Thesis and 12 M.Tech thesis and 04 are under progress. Her areas of interst include Electromagnetics, Microwave Comm, Wireless communication and Antenna Design. 